\title{
CORONAVÍRUS e desafios para o atendimento odontológico
}

\author{
CORONAVIRUS and challenges for dental care \\ CORONAVIRUS y desafíos para el cuidado dental
}

Recebido: 13/03/2021 | Revisado: 19/03/2021 | Aceito: 22/03/2021 | Publicado: 31/03/2021

\author{
Rosana Apolonio Reis Andrade \\ ORCID: https://orcid.org/0000-0003-3195-0212 \\ Universidade Federal de Sergipe, Brasil \\ E-mail: rosana.apolonio@gmail.com \\ Alisson Augusto Gois de Almeida \\ ORCID: https://orcid.org/0000-0001-6027-946X \\ Universidade Federal de Sergipe, Brasil \\ E-mail: alisonalmeida.odo@gmail.com \\ Isadora Maria Batista da Silva Mota \\ ORCID: https://orcid.org/0000-0003-4174-368X \\ Universidade Federal de Sergipe, Brasil \\ E-mail: isa.batista.mota@gmail.com \\ Regiane Cristina do Amaral \\ ORCID: https://orcid.org/0000-0002-9191-0960 \\ Universidade Federal de Sergipe, Brasil \\ E-mail: amaralre@yahoo.com.br
}

\begin{abstract}
Resumo
No Brasil, o primeiro caso de COVID-19 surgiu no dia 26 de fevereiro de 2020. Os governantes, juntamente com o Ministério da Saúde e Organização Mundial de Saúde, criaram medidas para conter a epidemia. Assim, objetiva-se relatar a experiência do Instituto de Promoção e de Assistência à Saúde de Servidores do Estado de Sergipe (IPESAÚDE) na prestação do atendimento odontológico no período da pandemia pelo COVID-19 entre abril a julho de 2020, traçar um comparativo entre o número de atendimento e especialidades procuradas no mesmo período em 2019, bem como apresentar os protocolos instituídos para a realização dos atendimentos odontológicos no momento da pandemia. Metodologia: Pesquisa descritiva do tipo transversal, que relatará o protocolo de atendimento odontológico e biossegurança adotado pelo IPESAÚDE durante a pandemia em comparativo ao período anterior. Resultados: Foram atendidos nos meses de abril a julho de 2020, 2110 pacientes, sendo restaurações definitivas os procedimentos mais prevalentes. No mesmo período do ano de 2019, foram atendidos 10557 pacientes. Ao se comparar as produções, verifica-se diferença estatisticamente significativa (Kruskall Wallis - seguido de Student Newman Keuls) entre os meses de 2020 e 2019. Em 2020 houve redução de 80,3\% nos atendimentos gerais quando comparados com o mesmo período de 2019. Nesta mesma época, houve redução de $80,1 \%$ na demanda de atendimentos na urgência. Houve mudanças em procedimentos de triagem e atendimentos, e protocolos de biossegurança foram instaurados. Conclusão: Houve redução inicial do número de atendimentos, havendo aumento significativo no mês de julho de 2020. Protocolos de biossegurança foram instaurados.
\end{abstract}

Palavras-chave: Infecções por coronavírus; Odontologia; Biossegurança.

\begin{abstract}
In Brazil, the first case of COVID-19 appeared on February 26, 2020. The government, together with the Ministry of Health and the World Health Organization, created measures to contain the epidemic. Thus, the objective is to report the experience of the Institute for the Promotion and Assistance to Health of Servants of the State of Sergipe (IPESAÚDE) in the provision of dental care during the pandemic period by COVID-19 between April and July 2020, to draw a comparison between the number of services and specialties sought in the same period in 2019, as well as presenting the protocols instituted for the performance of dental care at the time of the pandemic. Methodology: Descriptive cross-sectional research, which will report the dental care and biosafety protocol adopted by IPESAÚDE during the pandemic as compared to the previous period. Results: In the months of April to July 2020, 2110 patients were treated, with permanent restorations being the most prevalent procedures. In the same period of 2019, 10557 patients were treated. When comparing the productions, there is a statistically significant difference (Kruskall Wallis followed by Student Newman Keuls) between the months of 2020 and 2019. In 2020 there was a reduction of $80.3 \%$ in general services when compared to the same period in 2019. At the same time, there was a reduction of $80.1 \%$ in the demand for emergency care. There have been changes in screening and care procedures, and biosafety protocols have been put in place. Conclusion: There was an initial reduction in the number of visits, with a significant increase in July 2020. Biosafety protocols were implemented.
\end{abstract}


Keywords: Coronavirus infections; Dentistry; Biosafety.

\section{Resumen}

En Brasil, el primer caso de COVID-19 apareció el 26 de febrero de 2020. El gobierno, junto con el Ministerio de Salud y la Organización Mundial de la Salud, crearon medidas para contener la epidemia. Así, el objetivo es dar a conocer la experiencia del Instituto de Promoción y Atención a la Salud de los Servidores del Estado de Sergipe (IPESAÚDE) en la prestación de atención odontológica durante el período pandémico por COVID-19 entre abril y julio de 2020, a hacer una comparación entre el número de servicios y especialidades buscados en el mismo período de 2019, así como presentar los protocolos instituidos para la realización de la atención odontológica en el momento de la pandemia. Metodología: Investigación descriptiva transversal, que reportará el protocolo de atención odontológica y bioseguridad adoptado por IPESAÚDE durante la pandemia en comparación con el período anterior. Resultados: En los meses de abril a julio de 2020 se trataron 2110 pacientes, siendo las restauraciones permanentes los procedimientos más prevalentes. En el mismo período de 2019 se trató a 10557 pacientes. Al comparar las producciones, existe una diferencia estadísticamente significativa (Kruskall Wallis - seguido por Student Newman Keuls) entre los meses de 2020 y 2019. En 2020 hubo una reducción del 80,3\% en los servicios generales respecto al mismo período de 2019 en Al mismo tiempo, hubo una reducción del 80,1\% en la demanda de atención de emergencia. Ha habido cambios en los procedimientos de detección y atención, y se han implementados protocolos de bioseguridad. Conclusión: Hubo una reducción inicial en el número de visitas, con un aumento significativo en julio de 2020. Se implementaron protocolos de bioseguridad.

Palabras clave: Infecciones por coronavírus; Odontologia; Bioseguridad.

\section{Introdução}

A pandemia da doença coronavírus (COVID-19), originária de Wuhan, China, tornou-se um grande desafio à saúde pública por ter se espalhado pelo mundo e atingindo muitos indivíduos. Seu contágio acontece por gotículas por via área de pessoas contaminadas, toque de mão, gotículas de saliva, espirro, tosse, catarro ou objetos ou superfícies contaminadas (Brasil, 2020) tendo período de incubação de 5 a 6 dias em média (Backer et al., 2020; Li et al., 2020; Meng et al., 2020). Entre os sintomas tem-se febre e tosse seca, falta de ar, fadiga e outros sintomas atípicos, como dor muscular, confusão, dor de cabeça, dor de garganta, diarreia e vômito (Chen et al., 2020; Guan et al., 2020). Sendo que alguns indivíduos desenvolvem complicações agudas severas.

No Brasil o primeiro caso surgiu no dia 26 de fevereiro de 2020 e a partir deste fato novos casos foram surgindo em diferentes regiões do país. Os governantes juntamente com o Ministério da Saúde e Organização Mundial de Saúde (Brasil, 2020), criaram medidas para conter a pandemia. Como exemplos de contenção foram criadas barreiras sanitárias entre as cidades, fechamento de comércio considerado não essencial, uso obrigatório de máscaras em locais públicos (Brasil, 2020). No campo da saúde, criação de centros de atendimentos aos sintomáticos respiratórios, suspensão de cirurgias e atendimento clínico eletivos e o atendimento odontológico somente em casos considerados de urgência (SAPS, 2020).

Para o atendimento odontológico há um risco aumentado, visto que o SARS-CoV-2 ("Severe Acute Respiratory Syndrome Coronavirus 2") pode ser detectado na saliva em várias formas, tais como: no trato respiratório inferior e superior quando o mesmo entra em contato direto com a cavidade oral, contaminando-a (Zhu et al., 2020; Zhu et al., 2020; Zou et al., 2020, To et al., 2020); o vírus estando presente no sangue pode acessar a cavidade oral via fluido crevicular gengival, através do exsudato específico que contém proteínas locais derivadas da matriz extracelular e proteínas derivadas do soro; ainda o SARS-CoV-2 pode estar presente na cavidade oral pela infecção das glândulas salivares menores e maiores, com subsequente liberação de partículas virais na saliva via ductos salivares (Xu et al., 2020; Silva-Boghossian et al., 2020; Sabino-Silva et al., 2020; To et al., 2020; Franco et al., 2020).

Assim, por se tratar de uma infecção respiratória, a qual o tipo e a forma de transmissão através de gotículas provenientes da tosse, fala, espirro, (tamanho partícula $>5 \mu \mathrm{m}$ (micrómetro), que atinge até $1 \mathrm{~m}$ (metro) de distância do paciente fonte, com tempo de permanência em segundos no ar e devido ao uso dos aerossóis, há a necessidade de escolhas mais 
criteriosas dos Equipamentos de Proteção Individual (EPI) a serem utilizados pela equipe de profissionais da odontologia. (Franco et al., 2020).

Estas situações em que há a possibilidade de espalhamento do vírus é necessário que sejam instituídos protocolos específicos de biossegurança para se trabalhar com a segurança necessária como forma de conter a disseminação entre paciente e profissionais. Segundo Meng e colaboradores (2020), o risco de contaminação é aumentando tanto para profissionais como para os pacientes devido ao aerossol vinculado ao instrumento odontológico, que faz com que haja propagação maior do vírus para o ambiente (Meng et al., 2020).

Durante esse período da pandemia os órgãos governamentais publicaram atos administrativos que serviram de base, juntamente com as recomendações apresentadas por instituições da área da saúde com respaldo em âmbito internacional, nacional e local, para a normatização dos processos de trabalho em âmbito da saúde, fosse em ambientes de equipamentos de saúde públicos ou particulares (OPAS, 2020).

Em Sergipe, o Decreto Estadual no 40.560/20 publicado em 16 de março de 2020, regulamentou as medidas para enfrentamento da crise de saúde pública de importância internacional, nos termos da Lei Federal 13.979, de 06 de fevereiro de 2020. Entres essas medidas houve a suspensão dos atendimentos de saúde definidos como procedimentos eletivos, para atendimento médico ou odontológico tanto para o paciente suspeito ou positivado para o coronavírus, como o saudável, o atendimento deveria ser postergado, conforme recomendações da Associação de Medicina Intensiva Brasileira (AMIB) e do Conselho Federal de Odontologia (CFO). Foi recomendado o isolamento domiciliar, do tipo quarentena, para os pacientes suspeitos ou positivados e apenas nos casos de maior necessidade e/ou agravamento dos sintomas o paciente deveria procurar os serviços de saúde para atendimento odontológico (FUNESA).

Dentro dessa conformidade, o Instituto de Promoção e de Assistência à Saúde de Servidores do Estado de Sergipe IPESAÚDE, autarquia vinculada ao Governo do Estado de Sergipe, publicou a Portaria № 62/2020, de 24 de março de 2020, que dispôs a sobre a aplicação do Decreto Estadual no 40.560/20 e de medidas de prevenção a disseminação do covid-19 no âmbito do IPESAÚDE. Houve a suspensão de todos os atendimentos odontológicos nas unidades de saúde do interior (Itabaiana, Lagarto, Propriá, Estância e Nossa Senhora das Dores) e dos atendimentos eletivos e marcação de consultas no Centro Odontológico localizado em Aracaju. Objetivando regular a manutenção do funcionamento da urgência odontológica foi estabelecia a criação de um protocolo específico para enfrentamento da crise de saúde e pandemia pelo COVID-19.

Foram construídos o Protocolo de Atendimento de Urgência Odontológica Clínica do IPESAÚDE, que tomou como base as recomendações da American Dental Association (ADA), do CROSE (Conselho Regional de Odontologia de Sergipe), SINODONTO/SE (Sindicato dos Cirurgiões Dentista de Sergipe), do Protocolo Clínico de Urgências Odontológicas/Dourados/MS e o instrutivo com Orientações para Serviços de Saúde: medidas de prevenção e controle que devem ser adotadas durante o enfrentamento ao COVID-19 construído pela equipe interna do IPESAÚDE para ser utilizado na organização interna dos serviços.

Estes documentos normatizaram os atendimentos nos casos de urgência odontológica durante o enfrentamento ao COVID-19, respaldado pelas publicações da OMS (Organização Mundial de Saúde), normas e protocolos de biossegurança do Ministério da Saúde (ANVISA - Agência Nacional de Vigilância em Saúde), atrelados ao perfil da oferta dos serviços odontológico aos beneficiários que é de urgência odontológica clínica.

Dessa forma, foram definidos o elenco das patologias classificadas dentro das Urgências Odontológicas passíveis da realização de procedimentos pelos Cirurgiões-Dentistas: Pulpites, Algias dentárias, Pericoronarites, Osteítes/Alveolites, Hemorragia bucais, Luxação da ATM (Articulação Temporo Mandibular), Abscessos Periapicais ou Periodontais ou Infecção bacteriana localizada, Fratura dentárias resultando em dor ou causando trauma nos tecidos moles, Traumas dentários e remoção de suturas. 
Assim, os objetivos do presente estudo foram relatar a experiência do IPESAÚDE na prestação do atendimento odontológico no período da pandemia pelo COVID-19 nos meses de abril a julho de 2020, traçar um comparativo entre o número de atendimento e especialidades procuradas no mesmo período em 2019, bem como mostrar os protocolos e normas instituídas para a realização dos atendimentos odontológicos no momento da pandemia.

\section{Metodologia}

Este estudo teve aprovação do comitê de ética em pesquisa da Universidade Federal de Sergipe (CAAE: 35294820.3.0000.5546).

O Instituto de Promoção e de Assistência à Saúde de Servidores do Estado de Sergipe - IPESAÚDE, é uma autarquia vinculada ao governo estadual que presta serviços de promoção e de assistência à saúde de servidores do Estado de Sergipe. um convênio de saúde dos servidores do Estado do Sergipe. Atualmente também abrange o serviço a servidores de prefeituras conveniadas.

Entre os serviços oferecidos há o serviço odontológico (IPES Saúde Odontologia) que conta com as especialidades: clínica geral, odontopediatria, endodontia, atendimento a pacientes especiais, periodontia, cirurgia buco-maxilo-facial, radiologia, prevenção, urgência e perícia.

Para o atendimento nos períodos de pandemia, foi se instituído um protocolo de recepção dos pacientes que procuraram por atendimento.

\section{População incluída}

A população estudada foi composta por usuários que são beneficiários dos serviços de saúde do IPESAÚDE que é um convênio de saúde dos servidores do Estado do Sergipe e abrange servidores de algumas prefeituras conveniadas. Como tamanho da amostra foram de aproximadamente 4000 usuários (pacientes atendidos no Centro Odontológico do IPESAÚDE nos meses de abril a junho de 2020), 12.104 (pacientes atendidos no Centro Odontológico do IPESAÚDE nos meses de abril a junho de 2019) incluindo qualquer faixa etária, qualquer sexo ou raça, ou etnia. Assim foram incluídos na amostra todos os pacientes que procuraram por atendimento odontológico no período de abril a junho de 2020 e de abril a junho de 2019 . Alguns deles passaram apenas por consulta e receberam apenas medicação e outros atendimentos odontológicos, todos foram incluídos na pesquisa.

\section{Análise dos dados}

Foram realizadas análises comparativas, Kruskall Wallis, comparando produções clínicas nos meses de março a julho de 2019 e março a julho de 2020. Foi utilizado o programa estatístico Bioestat 5.0. Foram realizadas análises descritivas do protocolo seguido e mudanças realizadas.

\section{Resultados}

\section{Protocolo seguido e mudanças realizadas}

As práticas adotadas pelo IPESAÚDE e referendadas no Manual de Orientações para Serviços de Saúde: medidas de prevenção e controle que devem ser adotadas durante o enfrentamento ao COVID-19 foram construídas a partir do entendimento que todo serviço de saúde deve garantir que as práticas e atividades minimizem à exposição aos patógenos respiratórios, incluindo no atual momento a preocupação com o novo Coronavírus (SARS-CoV-2). A adoção de medidas de prevenção e controle são necessárias para resguardar os profissionais de saúde de uma possível infecção, bem como evitar/diminuir a disseminação do vírus circulante entre os pacientes e os outros servidores administrativos (recepção, limpeza, 
vigilantes). Por isso devem contemplar desde a chegada do paciente, triagem, espera, atendimento e finalização da assistência prestada, conforme Quadro 1.

Sala de espera e recepção: Diminuição de pessoas circulantes (permissão de acompanhantes apenas para crianças, idosos ou pessoas com deficiências ou casos justificados), espaçamento entre as cadeiras na sala de espera, colocação de barreiras de proteção de vidro na bancada da recepção, obrigatoriedade do uso de máscara durante ao aguardo para o atendimento, disponibilização de álcool a 70\%.

Acolhimento e Triagem do paciente antes do atendimento: Orientação inicial para lavagem das mãos e rosto com água e sabão no banheiro. Esclarecimento pela equipe da recepção sobre a necessidade de preenchimento de um questionário, conforme é apresentado no quadro seguinte.

Quadro 1. Checklist para Avaliação de Sinais e Sintomas do Covid-19:

\begin{tabular}{|c|c|c|c|c|}
\hline \multicolumn{5}{|l|}{ PERGUNTAS } \\
\hline \multirow{5}{*}{$\begin{array}{l}\text { Você tem sintomas de } \\
\text { gripe? }\end{array}$} & Tosse & \multicolumn{2}{|l|}{ SIM ( ) } & $\mathrm{NÃO}(\quad)$ \\
\hline & Coriza & \multicolumn{2}{|l|}{$\operatorname{SIM}(\quad)$} & NÃO ( ) \\
\hline & Dor de garganta & \multicolumn{2}{|l|}{$\operatorname{SIM}(\quad)$} & $\mathrm{NÃO}(\quad)$ \\
\hline & Febre & \multicolumn{2}{|l|}{$\operatorname{SIM}(\quad)$} & $\mathrm{NÃO}($ ) \\
\hline & Falta de ar & \multicolumn{2}{|l|}{ SIM ( ) } & NÃO ( ) \\
\hline \multirow{3}{*}{$\begin{array}{l}\text { Você tem algum desses } \\
\text { sintomas? }\end{array}$} & Diarreia & $\operatorname{SIM}(\quad)$ & & NÃO ( ) \\
\hline & Perda do olfato & $\operatorname{SIM}(\quad)$ & & NÃO ( ) \\
\hline & Perda de paladar & $\operatorname{SIM}(\quad)$ & & NÃO ( ) \\
\hline $\begin{array}{l}\text { Você está tendo fere } \\
\text { persistente ou falta de ar? }\end{array}$ & \multicolumn{2}{|l|}{$\operatorname{SIM}(\quad)$} & \multicolumn{2}{|l|}{ NÃO ( ） } \\
\hline $\begin{array}{l}\text { Você teve contato com } \\
\text { alguém que estava } \\
\text { diagnosticado } \\
\text { COVID-19? }\end{array}$ & $\operatorname{SIM}(\quad)$ & & $\mathrm{NÃO}(\quad)$ & \\
\hline
\end{tabular}

Fonte: IPESAÚDE.

Consultório odontológico: Na sequência o paciente era encaminhado para avaliação pelo cirurgião-dentista acerca do questionário sobre o COVID-19 e inserção da anamnese no Prontuário Eletrônico (implementado para esse momento da pandemia). Pacientes com sintomas gripais e/ou com suspeitas de COVID-19, recebiam orientações e eram encaminhados para o Centro de Tratamento para Síndrome Gripal do IPESAÚDE. Quanto ao atendimento odontológico, o profissional deveria seguir o protocolo instituído, sendo facultando ao profissional a viabilidade ou não do atendimento naquele momento, podendo o paciente ser medicado e solicitado o retorno após a quarentena.

Houve a necessidade de reforma e adequações para que todos os consultórios funcionassem de forma individualizada, com separação dos consultórios conjugados e uso preferencial dos consultórios com instalação de bomba à vácuo durante a execução de procedimentos com dispersão de aerossóis.

Antes do início dos atendimentos era solicitado aos pacientes que realizassem bochecho com solução de peróxido de hidrogênio a $1 \%$ durante 01 minuto para posterior início de intervenção na cavidade oral a realização de (Mata et al., 2020).

Foram revistos e implementados o Procedimento Operacional Padrão (POP) - Padronização de Normas e Rotinas de Biossegurança do Centro Odontológico Maria Viana Bragança, para enfrentamento da Pandemia pelo COVID-19, que era a única de saúde do IPESAÚDE em que estava disponível para os atendimentos de urgência odontológica. O protocolo quanto ao uso dos EPIs (Quadro 2), os procedimentos de higienização, desinfecção e esterilização realizados (Quadro 3) e a organização das agendas e processos de trabalho dos profissionais (Quadro 4). 
Quadro 2. Utilização dos Equipamentos de Proteção Individual (EPIs).

\begin{tabular}{|c|c|}
\hline $\begin{array}{lr}\begin{array}{l}\text { Profissionais } \\
\text { atuam }\end{array} & \text { que } \\
\text { atendimento } & \text { aos } \\
\text { pacientes } & \\
\text { Cirurgiões- } & \\
\text { dentistas } & \text { e } \\
\text { Auxiliares } & \text { de } \\
\text { Saúde } & \text { Bucal } \\
\text { (ASBs): }\end{array}$ & $\begin{array}{l}\text { - Gorro descartável- descartar no final do turno do atendimento ou trocar nos casos de algum procedimento mais } \\
\text { invasivo e com dispersão de aerossóis } \\
\text { - Máscara N95- individual e reutilizável. *Seguir as orientações específicas do fabricante } \\
\text { - Jaleco de tecido e por cima jaleco descartável } \\
\text { - Óculos de proteção e/ou Protetor Facial (Face shield) - proceder higienização/desinfecção após o atendimento de } \\
\text { cada paciente } \\
\text { - Limpeza e posterior desinfecção com álcool líquido a } 70 \% \text {, hipoclorito de sódio ou outro desinfetante } \\
\text { recomendado pelo fabricante. Caso o protetor facial tenha sujidade visível, deve ser lavado com água e } \\
\text { sabão/detergente e só depois dessa limpeza, passar pelo processo de desinfecção } \\
\text { - Propés e/ou sapatos fechados }\end{array}$ \\
\hline $\begin{array}{l}\text { Profissionais } \\
\text { estão } \\
\text { retaguarda } \\
\text { atendimento }\end{array}$ & $\begin{array}{l}\text { Sala de esterilização (ASBs): } \\
\text { - Máscara cirúrgica- descartar a cada } 03 \text { horas de trabalho ou na presença de umidade } \\
\text { - Gorro descartável- descartar no final do turno do atendimento } \\
\text { - Jaleco- Após a finalização do atendimento, retirar, colocar em sacola e levar para lavagem. } \\
\text { Recepção: } \\
\text { - Máscara cirúrgica- descartar a cada } 03 \text { horas de trabalho ou na presença de umidade } \\
\text { - Jaleco descartável- Após a finalização do atendimento, retirar, colocar em sacola plástica e levar para lavagem em } \\
\text { casa } \\
\text { Vigilante: } \\
\text { - Máscara cirúrgica- - descartar a cada } 03 \text { horas de trabalho ou na presença de umidade } \\
\text { Auxiliares de serviço de limpeza } \\
\text {-Máscara cirúrgica- descartar a cada } 03 \text { horas de trabalho ou na presença de umidade } \\
\text {-Fardamento- de tecido e por cima jaleco descartável: Após a finalização do atendimento, retirar o fardamento } \\
\text { colocar em sacola plástica e levar para lavagem } \\
\text { - Luvas de borracha- cuidado ao retirar, colocar } \\
\text { - Sapatos fechados- Após a finalização do atendimento, retirar, colocar em sacola e levar para lavagem em casa }\end{array}$ \\
\hline
\end{tabular}

Fonte: IPESAÚDE.

Quadro 3. Protocolo dos processos de higienização, desinfecção e esterilização.

- Limpeza das superfícies, bancada e equipo odontológico com álcool a $70 \%$ e troca do filme plástico do envelopamento no intervalo entre cada paciente;

- Limpeza do chão da sala e cuspideira com hipoclorito de sódio diluído em água.

- Imersão dos instrumentais em solução enzimática, lavagem com detergente, secagem, empacotamento, selagem e autoclavagem.

- Em procedimentos onde houve dispersão de aerossóis todos os instrumentos e equipamentos possíveis devem ser esterilizados na autoclavagem.

- As canetas de alta-rotação devem ser trocadas e esterilizadas em autoclave após o uso em cada paciente.

Fonte: IPESAÚDE.

Quadro 4. Organização das agendas e processos de trabalho dos profissionais.

- Agendamento dos pacientes deixa de ser de 20 min para intervalo entre paciente de 45 min.

- Quando da necessidade de atendimento em pacientes com síndrome gripal e uso de instrumentos com dispersão de aerossóis, reforçar os cuidados apontados nos protocolos de biossegurança e a sala de atendimento deverá ficar isolada por 2 horas com janelas abertas, antes do próximo atendimento.

- Para pacientes que precisam de reavaliação após atendimentos da urgência será feito contato no formato de tele consulta por um cirurgião-dentista que dará as orientações necessárias e/ou marcação de agendamento para os profissionais que atuam na retaguarda dos casos prioritários (complicações pós-exodontias, continuidade de intervenções endodônticas). 


\section{Comparativo no número de atendimentos realizados}

Foram atendidos nos meses de março a julho de 2020, 2273 pacientes, sendo a maior parte realizada em consultas no mês de março, restauração definitiva nos meses de abril a julho. No mesmo período do ano de 2019, foram atendidos 10557 pacientes.

Tabela 1. Grupo de procedimentos realizados por meses, durante a pandemia do COVID 19 fase de fechamento da cidade e nos mesmos meses do ano de 2019. Aracaju, 2020.

\begin{tabular}{lccllllll}
\hline & $\mathbf{2 0 1 9}$ & & & \multicolumn{2}{c}{$\mathbf{2 0 2 0}$} \\
\hline Especialidade & Abril & Maio & Junho & Julho & Abril & Maio & Junho & Julho \\
\hline Clínico & 2142 & 1860 & 1277 & 1494 & 76 & 152 & 345 & 305 \\
Endodontia & 105 & 150 & 150 & 121 & 34 & 74 & 62 & 92 \\
Cirurgia & 395 & 165 & 238 & 265 & 36 & 102 & 238 & 265 \\
Urgência & 650 & 486 & 150 & 196 & 79 & 25 & 63 & 128 \\
Periodontia & 321 & 107 & 136 & 149 & 4 & 6 & 9 & 15 \\
\hline
\end{tabular}

Fonte: IPESAÚDE.

De acordo com o levantamento realizado, nota-se que entre os meses de abril a julho de 2020, houve redução de 80,3\% nos atendimentos gerais do atendimento odontológico do IPESAÚDE em relação ao mesmo período do ano de 2019. Com relação à urgência odontológica, especificamente, houve redução de $80,1 \%$ na demanda de atendimentos nesse mesmo período.

Ao se comparar as produções, verifica-se diferença estatisticamente significativa, Kruskall Wallis - seguido de Student Newman Keuls, entre abril/2019 e abril/maio/ junho de 2020, entre maio/2019 e maio/2020 e entre junho/2019 e maio/2020 ( $\mathrm{p}<0.05)$.

\section{Discussão}

A atual pandemia de coronavírus, COVID-19, pertence a uma família de vírus conhecidos como Coronaviridae, de RNA de fita simples. Trata-se de uma emergência de saúde pública de preocupação global, no qual centros internacionais de controle e prevenção de doenças estão monitorando esse surto de doença infecciosa que continua evoluindo rapidamente e se espalhou exponencialmente em diversas partes do mundo (Moura et al., 2020).

Considerando que o SARS-CoV-2 foi recentemente identificado na saliva de pacientes infectados, o surto da COVID19 é um lembrete de que os Cirurgiões-Dentistas devam se preocupar na disseminação de doenças infecciosas respiratórias, principalmente referentes à formação de aerossóis durante o atendimento odontológico (Franco et al., 2020).

Em 23 de julho de 2020, o Brasil era o segundo país no ranking mundial em número de casos e óbitos e, portanto, considerado o epicentro da doença na América Latina, sendo responsável por mais de 2 milhões de casos e 80 mil mortes. A COVID-19 na região Nordeste do Brasil representa um grave problema de saúde pública e seu impacto pode ser maior, considerando o processo de interiorização e sua crescente expansão para áreas mais vulneráveis (Andrade et al., 2020). Em um estudo feito por Kerr e colaboradores (2020) com dados de até 21/07/2020, a maior incidência da COVID-19 entre os nove Estados da região Nordeste foi registrada em Sergipe (2049/100.000 hab.), seguido pela Paraíba (1713/100.000 hab.) e Ceará (1677/100.000 hab.). 
A Agência Nacional de Vigilância Sanitária (ANVISA) publicou notas técnicas que têm sido atualizadas com o decorrer da pandemia. Nessas notas ficaram estabelecidas regras para a assistência odontológica, inclusive diferenciando os cuidados em diferentes cenários: consultório/ambulatório, o ambiente hospitalar e a unidade de terapia intensiva (UTI). O documento da ANVISA restringiu os procedimentos odontológicos ao atendimento de urgências e emergências; deu ênfase aos cuidados com a anamnese criteriosa, com a sala de espera e com os equipamentos de proteção individual (EPI); e recomendou a realização de bochecho com peróxido de hidrogênio 01 a 1,5\% prévio ao atendimento e o uso prioritário de dispositivos manuais ao atender para evitar gerar aerossóis (Carletto \& Dos Santos, 2020).

O presente estudo representa uma análise do número de pacientes que foram atendidos na urgência odontológica do IPES Saúde Odontologia em 2020 em relação ao mesmo período de 2019, verificando o possível impacto dos atendimentos neste cenário de pandemia da COVID-19. Além disso, apresentamos as medidas de biossegurança que foram adotadas a fim de evitar contaminação durante os atendimentos.

Orientações e recomendações para os cirurgiões-dentistas de acordo com o Protocolo de Atendimento de Urgência Odontológica Clínica do IPESAÚDE: 1-Os atendimentos odontológicos devem, preferencialmente, se restringirem ao alívio das dores severas e/ou risco de disseminação de infecção, com isso diminuindo o sofrimentos dos pacientes, bem como os encaminhamentos e procura pelos hospitais; 2 - Os dentistas devem usar seu julgamento profissional para determinar a necessidade de um paciente para atendimento de urgência ou emergência ou impedimento dele; 3 - Os procedimentos odontológicos devem ser tratados, quando possíveis, da menor forma invasiva, afim de se evitar propagação de contaminantes em detrimento à proteção aos profissionais e pacientes circulantes; 4 - Rigorosamente, todos os profissionais devem estar atentos e seguirem os princípios de biossegurança e esterilização recomendados pela ANVISA e Ministério da Saúde.

Os resultados indicam uma redução significativa, de $80,1 \%$, no número de pacientes atendidos na urgência odontológica no período mencionado, além de uma redução de 80,3\% nos atendimentos gerais (incluindo clínica-geral, endodontia, cirurgia, periodontia e a própria urgência), o que sugere que a COVID-19 interferiu diretamente na assistência odontológica e no comportamento dos pacientes, o que corrobora os resultados também encontrados por Huaqiu e colaboradores (2020) e Ju-Hui e colaboradores (2020).

Em relação à urgência odontológica do IPES Saúde Odontologia, no mês de abril de 2020 houve redução de $88 \%$ no número de atendimentos em comparação com o ano anterior. Em maio, houve redução de $95 \%$, sendo a maior redução registrada durante a pandemia. Em junho, a redução foi de 58\% e em julho, de 34,7\%.

Como a maior parte do atendimento odontológico de rotina não estava disponível durante o pico da pandemia, seja em consultórios públicos ou privados, esperava-se uma grande redução do número de atendimentos neste período, o que ocorreu. Entretanto, quando necessário, os pacientes procuraram por atendimento de urgência odontológica. Casos de lesão pulpar ou periapical, abscessos, pericoronarite, fraturas de dentes/restaurações, dentre outros, foram apontados.

Ao seguir as recomendações de isolamento preconizadas pelas autoridades competentes, muitas pessoas evitaram se expor e buscaram realizar somente atividades extremamente necessárias. Com isso, instituições de saúde também sentiram o impacto dessas medidas, e como resultado, a contagem geral de pacientes foi reduzida em $80,3 \%$ nos atendimentos odontológicos gerais no período mencionado.

De acordo com Guo e colaboradores (2020), embora a maior parte da atenção do público esteja se concentrando nas causas diretas e nas medidas de controle do COVID-19, as possíveis consequências para a saúde resultantes do medo das pessoas não devem ser negligenciadas, sendo necessário prever as futuras necessidades odontológicas decorrentes deste período de redução nos atendimentos.

Apesar do grande desafio de aplicar um novo protocolo baseado nas recomendações da OMS, do Ministério da Saúde, da ANVISA e demais órgãos competentes, as medidas de controle foram implementadas objetivando reduzir ao máximo o 
risco de contaminação e proteger pacientes e profissionais durante o atendimento clínico. Assim, foi possível manter o funcionamento do Centro Odontológico do IPESAÚDE para a demanda que foi apresentada.

No mês de julho de 2020, houve a menor redução em comparação com os meses anteriores, sugerindo uma perspectiva de retorno aos atendimentos habituais, obedecendo aos novos protocolos já efetivados.

\section{Conclusão}

A experiência vivenciada pelo IPESAÚDE demonstrou que no momento de enfrentamento à pandemia pelo COVID19 e da necessidade de se garantir a oferta de atendimento odontológico para os quadros de urgência clínica, houve a necessidade de mudanças em modelos de protocolos de biossegurança e do modo de atendimento. No início da pandemia houve redução significativa do número de atendimentos e conforme os protocolos foram inseridos e houve segurança por parte dos profissionais e pacientes o atendimento foi se regularizando. A criação de um novo protocolo de atendimento foi importante como barreira de proteção da disseminação do vírus tanto para profissionais como para pacientes, para evitar a desassistência e possíveis agravamentos dos quadros odontológicos apresentados pelos pacientes. Entretanto, como o evento do vírus é algo novo para todos, é importante compartilhar experiências e protocolos desenvolvidos como forma de contribuir em processos de planejamento com oferta da prestação de serviços para os pacientes e profissionais de forma segura. Como algo novo, há necessidade de novos e amplos estudos sobre o vírus, protocolos de atendimento ao paciente e impactos apresentados na assistência para o profissional e pacientes.

\section{Agradecimentos}

Ao IPESAÚDE de Aracaju, na figura do presidente Dr. Christian Oliveira.

\section{Referências}

American Dntal Association (2020) Covid-19 Resources for dentists. https://www.ada.org/en/member-center/coronavirus-resource-toolkitfor-adamembers

Andrade, L. A. et al. COVID-19 mortality in an area of northeast Brazil: epidemiological characteristics and prospective spatiotemporal modeling. Epidemiology and Infection, 148, E288.

Brasil. Ministério da Saúde. Coronavírus (COVID 19) (2020). https://coronavirus.saude.gov.br/sobre-a-doenca\#o-que-e-covid

Backer, J.A., Klinkenberg, D. \& Wallinga, J. (2020). Incubation period of 2019 novel coronavirus (2019-nCoV) infections among travellers from Wuhan, China, 20-28 January 2020. Euro Surveill., 25(5),2000062.

Carletto, A. F. \& Dos Santos, F. F. (2020). A atuação do dentista de família na pandemia do Covid-19: o cenário do Rio de Janeiro. Physis: Revista de Saúde Coletiva, 30(3), e300310.

Chen, N, Zhou, M., Dong, X., Qu, J., Gong, F., Han, Y., \& Zhang, L. (2020). Epidemiological and clinical characteristics of 99 cases of 2019 novel coronavirus pneumonia in Wuhan, China: a descriptive study.The Lancet, 395(10223), 507-513.

Conselho Federal de Odontologia (2020). Recomendações AMIB/CFO para atendimento odontológico COVID- 19: Comitê de Odontologia AMIB/CFO de enfrentamento ao COVID-19 Departamento de Odontologia AMIB - $1^{\circ}$ Atualização 25/03/2020. https://website.cfo.org.br/wpcontent/uploads/2020/03/AMIB_CFO-Recomendac\%cc\%a7o\%cc\%83es.pdf

Conselho Regional de Odontologia de Sergipe (2020). Manejo odontológico ambulatorial em tempos de COVID-19.http://crose.org.br/upload/manejoodontologico-ambulatorial-ok-crosecovid19_ddc5c919ed51d95cb02e12.pdf

Decreto $n^{\circ}$ 40560, de 16 de março de 2020. Dispõe sobre a decretação de situação de emergência na saúde pública do Estado de Sergipe, em razão da disseminação do vírus COVID-19 (novo coronavírus) e regulamenta as medidas para enfrentamento da crise de saúde pública de importância internacional, nos termos da Lei (Federal) no 13.979, de 06 de fevereiro de 2020. https://www.pge.se.gov.br/wp-content/uploads/2020/04/DECRETO-N\%C2\%BA-40.560DE-16032020-ESTADO-DE-SERGIPE.pdf

Faccini, M. Ferruzzi, F., Mori, A. A., Santin, G. C., Oliveira, R. C., De Oliveira, R. C. G., Freitas, K. M. S. (2020). Dental Care during COVID-19 Outbreak: A Web-Based Survey. Eur J Dent, 14(suppl S1), S14-S19.

Franco, J. B., De Camargo, A. R. \& Peres, M. P. S. M. (2020). Cuidados Odontológicos na era do COVID-19: recomendações para procedimentos odontológicos e profissionais. Rev assoc paul cir dent, 74(1),18-21. 
Guan, W-J., Ni, Z-Y., Hu, Y., Liang, W-H., Ou, C-Q., He, J-X., Zhong, N-S. (2020.) Clinical characteristics of 2019 novel coronavirus infection in China. N Engl J Med,382(18), 1708-1720.

Guo, H., Zhou, Y., Liu, X., Tan, J. (2020). The impact of the COVID-19 epidemic on the utilization of emergency dental services, Journal of Dental Sciences, $15,564-567$.

Kerr, L., Kendall, C., Silva, A. A. M. da, Aquino, E. M. L., Pescarini, J. M., Almeida, R. L. F. de, \& Barreto, M. L. (2020). COVID-19 no Nordeste brasileiro: sucessos e limitações nas respostas dos governos dos estados. Ciência \& Saúde Coletiva, 25(2),4099-4120.

Li, Q., Med., M., Guan, X., Wu, P., Wang, X., Zhou, L., \& Feng, Z. (2020). Early transmission dynamics in Wuhan, China, of novel coronavirus-infected pneumonia. N Engl J Med., 382(13),1199-1207.

Mata, I., Goes, A. R., \& Bizarra, M. F. (2020). A importância da higiene oral durante a pandemia: o caso das pessoas institucionalizadas. Escola Nacional de Saúde Pública de Lisboa. https://www.saudeoral.pt/destaques/opiniaoimportancia-da-higiene-oral-durante-a-pandemia-o-caso-das-pessoas-institucionalizadas

Meng, L., Hua, F. \& Bian, Z. (2020). Coronavirus Disease 2019. (COVID-19): Emerging and Future Challenges for Dental and Oral Medicine. Journal of Dental Research, 99(5) 481-487.

Moura, J. F. S., Moura, K. S., Pereira, R. S. \& Marinho, R. R. B. (2020). COVID-19: Dentistry in the face of the pandemic. Braz. J. Hea. Rev., 3(4), 72767285 .

OPAS. Organização Pan Americana de Saúde (2020). https://www.paho.org/pt/covid19

Petrescu, N. B., Aghiorghiesei, O., Mesaros, A. S., Lucacio, O. P., Dinu, C. M., Campian, R. S. \& Negucioiu, M. (2020). Impact of COVID-19 on Dental Emergency Services in Cluj-Napoca Metropolitan Area: A Cross-Sectional Study. Int. J. Environ. Res. Public Health, $17,7716$.

Portaria $n^{\circ}$ 62/2020, de 24 de março de 2020. Dispõe sobre a aplicação do decreto estadual no 40.560/20 e de medidas de prevenção a disseminação do covid19 no âmbito do Ipesaúde. https://www.ipesaude.se.gov.br/wp-content/uploads/2020/03/Portaria-COVID-19.pdf

Prefeitura Municipal de Dourados (2016). Protocolo clínico de urgências odontológicas na saúde bucal. https://www.dourados.ms.gov.br/wpcontent/uploads/2016/03/Microsoft-Word-PROTOCOLO-DE-URG\%C3\%8ANCIA-2\%C2\%AA-revis\%C3\%A3o.pdf

Sabino-Silva, R., Jardim, A. C. G. \& Siqueira, W. L. (2020). Coronavirus COVID-19 impacts to dentistry and potential salivary diagnosis. Clin Oral Investig, 24(4):1619-1621.

SAPS. Secretaria de Atenção Primária a Saúde (2020). https://aps.saude.gov.br/noticia/9996

Silva-Boghossian, C. M., Colombo, A. P., Tanaka, M., Rayo, C., Xiao, Y., Siqueira, W. L. (2013). Quantitative proteomic analysis of gingival crevicular fluid in different periodontal conditions. PLoS One, 8(10):e75898.

SINODONTO-SE. Sindicato dos Cirurgiões-Dentistas de Sergipe (2020) Orientações sobre biossegurança. http://sinodonto.org.br/novo/orientacoes-sobrebiosseguranca/

To, K. K-W., Tsang, O. T-Y., Yip, C. C-Y., Chan, K-H., Wu, T-C., Chan, J. M-C., Yuen, K-Y. (2020). Consistent detection of 2019 novel coronavirus in saliva. Clin Infect Dis, 71(15), 841-843.

Xu, H., Zhong, L., Deng, J., Peng, J., Dan, H., Zeng. X, Li, T. \& Chen, Q. (2020). High expression of ACE2 receptor of 2019-nCoV on the epithelial cells of oral mucosa. Int J Oral Sci, 12(1):8.

Wu, J-H., Lee, M-K., Lee, C-Y., Chen, N-H., Lin, Y-C., Chen, K-K., Lee, K-T., Du, JK. (2020). The impact of the COVID-19 epidemic on the utilization of dental services and attitudes of dental residents at the emergency department of a medical center in Taiwan. J Dent Sci,15(4),564-567.

Zhou, P., Yang, X-L., Wang, X-G., Hu, B., Zhang. L, Zhang, W., \& Shi, Z-L. (2020). A pneumonia outbreak associated with a new coronavirus of probable bat origin. Nature, 579(7798):270-273.

Zhu, N., Zhang, D., Wang, W., Li, X., Yang, B., Song, J., \& Tan, W. (2020). China Novel Coronavirus Investigating and Research Team. A Novel Coronavirus from Patients with Pneumonia in China, 2019. N Engl J Med, 382(8):727-733.

Zou, L., Ruan. F., Huang, M., Liang, L., Huang, H., Hong, Z., \& Wu, J. (2020). SARS-CoV-2 Viral Load in Upper Respiratory Specimens of Infected Patients. N Engl J Med, 382(12):1177-1179. 